Tropical Journal of Pharmaceutical Research December 2020; 19 (12): 2559-2563

ISSN: $1596-5996$ (print); 1596-9827 (electronic)

(C) Pharmacotherapy Group, Faculty of Pharmacy, University of Benin, Benin City, 300001 Nigeria

Available online at http://www.tjpr.org

Original Research Article

http://dx.doi.org/10.4314/tjpr.v19i12.11

\title{
Dexmedetomidine mitigates lipopolysaccharide-induced acute lung injury in septic rats via inhibition of NF-KB associated anti-inflammatory pathway
}

\author{
Hongcheng Zang*, Gang Shao \\ Department of Anesthesiology, The First People's Hospital of Fuyang District, Hangzhou 311400, PR China \\ *For correspondence: Email: j618zn@163.com
}

Sent for review: 29 July 2020

Revised accepted: 15 November 2020

\begin{abstract}
Purpose: To investigate the effect of dexmedetomidine in a rat model of acute lung injury (ALI), and the underlying mechanism.

Methods: Acute lung injury (ALI) was induced in adult male Sprague Dawley rats $(n=27)$ using lipopolysaccharide (LPS). Three rat groups were used (9 rats/group): untreated control, LPS and treatment groups. Pathological lesions in rat pulmonary tissues were assessed and inflammatory scores determined. The levels TNF- $\alpha$ and IL-6 in BALF were determined using their respective enzyme-linked immunosorbent assay (ELISA) kits, while protein levels of $p-I K B$ and NF-KB p65 were assessed by Western blotting.

Results: Lung tissue damage was markedly mitigated in treatment mice, relative to LPS mice $(p<$ 0.05). Inflammatory scores and population of neutrophils and macrophages increased significantly in LPS mice, relative to control, but decreased by dexmedetomidine exposure $(p<0.05)$. Similarly, TNF- $\alpha$ and IL-6 levels in pulmonary tissue homogenates of LPS rats were increased, relative to control rats, but were downregulated by dexmedetomidine exposure $(p<0.05)$. Moreover, dexmedetomidine downregulated the expressions of $p-I K B$ and NF-kB p65 in pulmonary tissues $(p<0.05)$.

Conclusion: Dexmedetomidine mitigates LPS-induced $A L I$ in rats by blocking the activation of NF-KB and IKB, coupled with inhibition of the secretion of TNF- $\alpha$ and IL-6.
\end{abstract}

Keywords: Acute lung injury, Dexmedetomidine, Inflammatory cytokines, NF-KB pathway, Sepsis

\begin{abstract}
This is an Open Access article that uses a funding model which does not charge readers or their institutions for access and distributed under the terms of the Creative Commons Attribution License (http://creativecommons.org/licenses/by/4.0) and the Budapest Open Access Initiative (http://www.budapestopenaccessinitiative.org/read), which permit unrestricted use, distribution, and reproduction in any medium, provided the original work is properly credited.
\end{abstract}

Tropical Journal of Pharmaceutical Research is indexed by Science Citation Index (SciSearch), Scopus, International Pharmaceutical Abstract, Chemical Abstracts, Embase, Index Copernicus, EBSCO, African Index Medicus, JournalSeek, Journal Citation Reports/Science Edition, Directory of Open Access Journals (DOAJ), African Journal Online, Bioline International, Open-J-Gate and Pharmacy Abstracts

\section{INTRODUCTION}

Sepsis manifests when chemicals released into the systemic circulation to combat infection induce widespread inflammation in tissues. This causes a sequence of lesions affecting multiple organs, leading to death in some cases. The symptoms of sepsis manifest in high body temperature, breathlessness, hypotension, abnormal heart beat and mental confusion. Sepsis occurs commonly in severe burns, multiple injuries and other diseases. It leads to acute lung injury (ALI) and other complications, often characterized by aggregation of inflammatory cells and hydrops in the lungs, and pulmonary dysfunction. Sepsis treatment involves the use of antibiotics, intravenous fluids and mechanical ventilation [1,2]. The 
pathogenesis of sepsis is not completely understood, and remains an area of concern for many investigators.

Acute lung injury (ALI) accounts for $40 \%$ morbidity and mortality (40\%) in critically-sick populations. It refers to acute onset of bilateral lung infiltrations with hypoxemia, in the absence of hydrostatic pulmonary edema [3]. Strategies presently employed for the treatment of sepsis cannot effectively mitigate ALI [4].

Nuclear factor kappa-light chain enhancer of activated $B$ cells (NF-KB) regulates transcription of DNA, cytokine secretion and cell viability. On binding to target genes in the nucleus, it promotes the transcription, translation and secretion of TNF- $\alpha$ and IL- 6 , which in turn mediate ALI [5,6]. Dexmedetomidine, a new generation of highly selective $\alpha 2$-adrenergic receptor $(\alpha 2-A R)$ agonist, produces sedative, delirium-lowering, cardio-protective and lungprotective properties [7]. Studies have shown that when given in the right dose, dexmedetomidine significantly reduces brain damage while promoting neurological function recovery in rats after local cerebral ischemia reperfusion [8]. However, little or nothing is known about the relationship amongst dexmedetomidine, NF-kB signaling pathway and $\mathrm{ALI}$. The present investigation was carried out to study the influence of dexmedetomidine on rat model of $A L I$, and the mechanism involved.

\section{EXPERIMENTAL}

\section{Materials}

Lipopolysaccharide (LPS) was purchased from Beijing Cargill Biotechnology Co. Ltd; dexmedetomidine was obtained from Nanjing Saihongrui Biotechnology Co. Ltd, and bicinchoninic acid (BCA) protein kit was a product of Shanghai Rongbai Biotechnology Co. Ltd. Mouse IL-6 and TNF- $\alpha$ ELISA kits were bought from Shanghai Yagi Biotechnology Co. Ltd, and $H$ \& $E$ staining reagent was obtained from Jinclone (Beijing) Biotechnology Co. Ltd. Rabbit anti-mouse IkB, p-IkB, NF-kB p65 and $\beta$ actin monoclonal antibodies were products of Wuhan Purity Biotechnology Co. Ltd, while goat anti-rabbit IgG secondary antibody was obtained from Wuhan Feng Biotechnology Co. Ltd. Cryogenic $\left(-80{ }^{\circ} \mathrm{C}\right)$ refrigerator was purchased from Qingdao Haier Biomedical Co. Ltd. Inverted microscope and cryogenic high-speed centrifuge were products of Beijing Ganming Gene Technology Co. Ltd.
This research received approval from the Animal Ethical Committee of Department of Anesthesiology, The First People's Hospital of Fuyang District, Hangzhou 311400, PR China (approval no. 201946338), and carried out according to Principles of Laboratory Animal Care [9].

\section{Rats}

Adult male Sprague Dawley rats $(n=27)$ weighing $200-260 \mathrm{~g}$ (mean weight $=230 \pm 30$ g) were obtained from Red Liver Disease Research Co. Ltd. (Shanghai) \{(SCXK (Shanghai) 2019-0009)\}. The rats were housed in metal cages under standard conditions and allowed free access to standard feed and water. Prior to commencement of study, the rats were acclimatized to the laboratory environment for 3 days. Thereafter, they were kept in an environment with equal darkness and light periods at $24 \pm 2{ }^{\circ} \mathrm{C}$ and $40-70 \%$ humidity. The study received approval from the Institutional Animal Care and Use Committee, and the study procedures were carried out in line with the guidelines of Association for the Assessment and Accreditation of Laboratory Animal Care International.

\section{Experimental design}

Three rat groups were used (9 rats/group): untreated control, LPS, and treatment groups. With the exception of normal control group, the rats were injected intraperitoneally with LPS (10 $\mathrm{mg} / \mathrm{kg}$ to induce ALI. Rats in the treatment group also received $40 \mathrm{~g}$ dexmedetomidine/kg bwt 15 min after LPS administration. Rats in the normal control group received equivalent volume of normal saline intraperitoneally in place of LPS group. After $2 \mathrm{~h}$ of treatment, the rats were anesthetized via intraperitoneal injection of chlorohydrin. Lung tissue and BALF were then collected for analysis.

\section{Histopathological analysis}

Hematoxylin and eosin (H \& E) staining was used to assess pulmonary lesions, while cells in BALF were differentiated using Ruijemsa staining. The macrophages and neutrophils were counted using an inverted microscope.

\section{Determination of levels of inflammatory factors}

The levels of TNF- $\alpha$ and IL- 6 in homogenates of rat lung tissues were determined using their respective ELISA kits. 


\section{Histological scores for lung damage}

Total histological score was taken as total score for each parameter (degree of pulmonary injury, alveolar collapse, bronchial epithelial hyperplasia/metaplasia; bronchial mucus, and total inflammatory cells). The scores ranged from 0 to 4 , and the higher the histologic score, the more impaired the lung.

\section{Western blotting}

Cell suspension resulting from trypsinization of lung tissues was rinsed twice with PBS and lysed with RIPA buffer mixed with protease and phosphatase inhibitors (v:v $=1: 5$ ), followed by centrifugation for $10 \mathrm{~min}$ at $12000 \mathrm{rpm}$ at $4{ }^{\circ} \mathrm{C}$. Following protein quantification using $\mathrm{BCA}$ method, standard procedures for Western blotting were carried out. These entailed SDSPAGE, electro-blotting onto PVDF membranes, blocking of non-specific binding of the blot, incubation of the membranes overnight at $4{ }^{\circ} \mathrm{C}$ with appropriate primary antibodies, incubation with horse radish peroxidase-linked secondary antibody, and blot development with X-ray film. Then, ECL was employed for analyzing the bands. $\beta$-Actin gene was used as standard.

\section{Statistical analysis}

The results are presented as mean \pm SEM, and were statistically analyzed using SPSS (version 23.0) software. Two-group comparisons were done with $t$-test. Values of $p<0.05$ were taken as indicative of significant differences.

\section{RESULTS}

\section{Pulmonary lesions in rats}

Normal control rats exhibited normal lung morphology without exudation of neutrophils, red blood cells (RBCs) and edema fluid. Alveolar wall thickness of rats in LPS group was significantly increased, and a large number of neutrophils and RBCs exuded from the blood vessels, accompanied by edema fluid. However, lung tissue damage was significantly mitigated (the exudation of neutrophils, RBCs and edema fluid was significantly reduced) in treatment group, relative to LPS rats $(p<0.05$; Figure 1$)$.

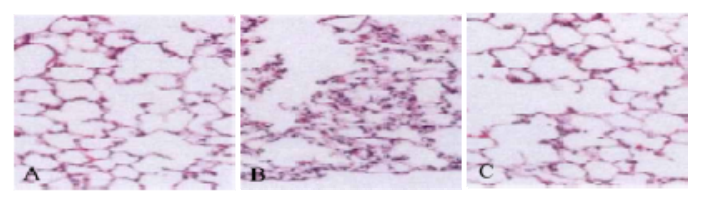

Figure 1: Pathological changes in lung tissues of rats. A: Normal control group; B: LPS group; C: treatment group

\section{Inflammation score and population of inflammatory cells in BALF}

As shown in Table 1, inflammatory scores and the population of neutrophils and macrophages were markedly increased in LPS group, relative to normal control rats, but the levels of these parameters were markedly decreased by treatment with dexmedetomidine $(p<0.05)$.

\section{Levels of inflammatory cytokines in pulmonary homogenates}

Table 2 shows that TNF- $\alpha$ and IL-6 levels in pulmonary tissue homogenates of rats in LPS group were markedly increased, relative to normal control rats, but were significantly reduced by dexmedetomidine treatment $(p<$ 0.05 ; Table 2).

\section{Levels of p-IkB and NF-kB p65 in lung tissues}

Dexmedetomidine significantly downregulated the protein expressions of $\mathrm{p}-\mathrm{IKB}$ and NF-KB p65 in pulmonary tissues of $A L I$ rats $(p<0.05$, Figure 2 and Table 3).

\section{DISCUSSION}

Sepsis, a leading cause of death in trauma and surgical patients, principally affects the lungs. It damages lung epithelial cells, thereby decreasing the barrier function of alveolar capillaries, resulting in pulmonary edema [10]. A major setback in the treatment of sepsis is the inability of health care providers to select appropriate and effective measures that can sufficiently block the inflammatory response in the lungs.

Dexmedetomidine promotes the activation of cholinergic anti-inflammatory pathways and induction of macrophage surface $\alpha-7$ nAChR, a key regulator of NF-KB activity. It blocks the

Table 1: Inflammatory scores and number of inflammatory cells (mean $\pm S D, n=9$ )

\begin{tabular}{llll}
\hline Group & Inflammatory score & Neutrophils $\left(\times 10^{7} / \mathrm{mL}\right)$ & Macrophages $\left(\times 10^{7} / \mathbf{m L}\right)$ \\
\hline Normal control & $2.43 \pm 0.15$ & $1.64 \pm 0.25$ & $0.12 \pm 0.04$ \\
LPS & $14.56 \pm 2.18^{\mathrm{a}}$ & $4.89 \pm 0.31^{\mathrm{a}}$ & $0.37 \pm 0.08^{\mathrm{a}}$ \\
Treatment & $5.03 \pm 0.25^{\mathrm{b}}$ & $2.89 \pm 0.29^{\mathrm{b}}$ & $0.19 \pm 0.05^{\mathrm{b}}$ \\
\hline
\end{tabular}

${ }^{\mathrm{a}, \mathrm{b}} P<0.05,{ }^{\mathrm{a}} \mathrm{vs}$ control; ${ }^{\mathrm{b}} \mathrm{vs}$ LPS rats 
Table 2: Levels of inflammatory cytokines in lung tissue homogenates (mean $\pm S D, n=9$ )

\begin{tabular}{lcc}
\hline Group & TNF- $\alpha(\mathbf{n m o l} / \mathrm{L})$ & IL-6 $(\boldsymbol{\mu m o l} / \mathrm{L})$ \\
\hline Normal control & $341.51 \pm 13.53$ & $55.95 \pm 3.01$ \\
LPS & $506.41 \pm 10.36^{\mathrm{a}}$ & $79.63 \pm 1.78^{\mathrm{a}}$ \\
Treatment & $364.51 \pm 7.36^{\mathrm{b}}$ & $58.40 \pm 2.08^{\mathrm{b}}$ \\
\hline $\mathrm{a}, \mathrm{b} P<0.05,{ }^{\mathrm{a}} \mathrm{vs}$ control; ${ }^{\mathrm{b}}$ vs LPS rats
\end{tabular}

Table 3: $p-I \kappa B$ and NF-KB p65 protein expressions in pulmonary tissues of rats (mean $\pm S D, n=9$ )

\begin{tabular}{lcc}
\hline Group & p-IKB/IKB & NF-kB p65/LaminB \\
\hline Normal control & $0.42 \pm 0.05$ & $0.69 \pm 0.05$ \\
LPS & $2.73 \pm 0.25^{\mathrm{a}}$ & $1.39 \pm 0.16^{\mathrm{a}}$ \\
Treatment & $0.80 \pm 0.19^{\mathrm{b}}$ & $0.78 \pm 0.10^{\mathrm{b}}$ \\
\hline $\mathrm{a}, \mathrm{b} P<0.05,{ }^{\mathrm{a}}$ vs control; ${ }^{\mathrm{b}}$ vs LPS rats
\end{tabular}

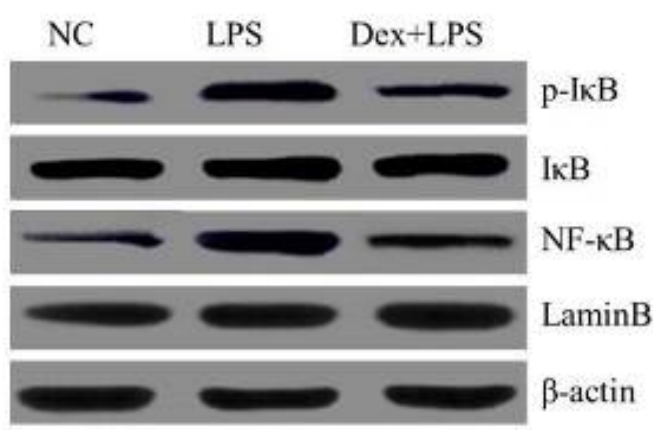

Figure 2: Comparison of degree of protein expressions of cytokines in lungs in each group

expression of NF-kB p65 and secretion of inflammatory cytokines, thereby alleviating systemic inflammatory responses [11]. It has been reported that catecholamine levels are increased in brain damage, and thatdexmedetomidine intervention significantly reduces the levels of these biogenic amines, thereby conferring protection on brain function. Results from an animal study have demonstrated that treatment of anesthetized dogs with dexmedetomidine significantly reduced blood flow in the brain without significantly altering the oxygen saturation of local brain tissues [12].

Inflammatory cytokines aggravate sepsisinduced inflammatory response. Macrophages and neutrophils are at the center of sepsisinduced inflammation. The binding of LPS to scavenger toll-like receptors on cell membrane promotes macrophage activation and the secretion of TNF- $\alpha$, IL- 6 and other inflammatory mediators, leading to vascular endothelial and alveolar epithelial cell damage, and ultimately pulmonary edema [13]. It is known that TNF- $\alpha$ is usually the first to be released, and a significant increase in its level results in damage to pulmonary capillary endothelial cells [14]. Together, TNF- $\alpha$ and IL- 6 stimulate neutrophil infiltration in pulmonary tissue, and subsequent over-activation of neutrophils could lead to tissue damage.

The results obtained in this study showed that histological score was significantly reduced, suggesting that lung tissue injury may have been significantly alleviated by dexmedetomidine. The numbers of neutrophils and macrophages were markedly elevated in LPS group, relative to normal control rats, but were significantly decreased by dexmedetomidine. It is likely that dexmedetomidine relieved $\mathrm{ALI}$ in septic rats by blocking the inflammatory pathway.

The NF-kB pathway has been shown to play a central role in the release of inflammatory cytokines. It participates in the onset and progression of sepsis and is closely related to the expression of related pro-inflammatory factors. In this way, it serves as an important pathway for macrophage aggregation and activation [15-17]. In this study, dexmedetomidine treatment significantly downregulated the expressions of $p$ IKB and NF-KB p65 in pulmonary tissues, an indication that dexmedetomidine may alleviate the severity associated with ALI by blocking the activation of $\mathrm{IKB}$ and NF-KB P65 in pulmonary tissues of septic rats.

\section{CONCLUSION}

The results obtained in this study suggest that dexmedetomidine mitigates LPS-induced ALI in rats by blocking the activation of $1 \mathrm{~KB}$ and NF-KB, and by inhibition of secretion of TNF- $\alpha$ and IL- 6 . This mechanism may be useful in the development of newer drugs for ALI.

\section{DECLARATIONS}

\section{Conflict of interest}

No conflict of interest is associated with this work.

\section{Contribution of authors}

We declare that this work was done by the author(s) named in this article and all liabilities pertaining to claims relating to the content of this article will be borne by the authors. All authors read and approved the manuscript for publication. Hongcheng Zang conceived and designed the study, Hongcheng Zang, Gang 
Shao collected and analyzed the data, while Hongcheng Zang wrote the manuscript.

\section{Open Access}

This is an Open Access article that uses a funding model which does not charge readers or their institutions for access and distributed under the terms of the Creative Commons Attribution License (http://creativecommons.org/licenses/by/ 4.0) and the Budapest Open Access Initiative (http://www.budapestopenaccessinitiative.org/rea d), which permit unrestricted use, distribution, and reproduction in any medium, provided the original work is properly credited.

\section{REFERENCES}

1. Coopersmith CM, De Backer D, Deutschman CS, Ferrer R, Lat I, Machado FR, Martin GS, Martin-Loeches I, Nunnally ME, Antonelli $M$, et al. Surviving Sepsis Campaign: Research Priorities for Sepsis and Septic Shock. Crit Care Med 2018; 46(8): 1334-1356.

2. Song $Y$, Chen $Y$, Dong $X$, Jiang $X$. Diagnostic value of neutrophil CD64 combined with CRP for neonatal sepsis: A meta-analysis. Am J Emerg Med 2019; 37(8): 1571-1576.

3. Wilson DC, Schefold JC, Baldirà J, Spinetti T, Saeed K, Elke G. Adrenomedullin in COVID-19 induced endotheliitis. Version 2. Crit Care 2020; 24(1): 411.

4. Meyer N, Harhay MO, Small DS, Prescott HC, Bowles KH, Gaieski DF, Mikkelsen ME. Temporal Trends in Incidence, Sepsis-Related Mortality, and Hospital-Based Acute Care After Sepsis. Crit Care Med 2018; 46(3): 354-360.

5. Tan HZ, Wu ZY, Wu JY, Long L, Jiao JW, Peng YH, Xu YW, Li SS, Wang W, Zhang JJ, et al. Single nucleotide polymorphism rs13042395 in the SLC52A3 gene as a biomarker for regional lymph node metastasis and relapse-free survival of esophageal squamous cell carcinoma patients. BMC Cancer 2016; 16: 560.

6. Ji $C L$, Jiang $H$, Tao $M Q, W u W T$, Jiang J, Zuo J. Selective regulation of IKK $/ N F-K B$ pathway involved in proliferation inhibition of HFLS-RA cells induced by 1,7dihydroxyl-3,4-dimethoxylxanthone. Kaohsiung $J$ Med Sci 2017; 33(10): 486-495.

7. Zhu YS, Xiong YF, Luo FQ, Min J. Dexmedetomidine protects rats from postoperative cognitive dysfunction via regulating the GABAB R-mediated CAMP-PKA-
CREB signaling pathway. Neuropathology 2019; 39(1): 30-38.

8. Meng Q, Guo P, Jiang Z, Bo L, Bian J. Dexmedetomidine inhibits LPS-induced proinflammatory responses via suppressing HIF1a-dependent glycolysis in macrophages. Aging (Albany NY) 2020; 12(10): 95349548.

9. World Health Organization. Principles of laboratory animal care. WHO Chron 1985; 39: 51-56.

10. Vallabhajosyula S, Pruthi S, Shah S, Wiley BM, Mankad SV, Jentzer JC. Basic and advanced echocardiographic evaluation of myocardial dysfunction in sepsis and septic shock. Anaesth Intensive Care 2018; 46(1): 1324.

11. Zhang A, Wang $P$, Ma $X$, Yin $X, L i J$, Wang $H$, Jiang $W$, Jia $Q$, Ni L. Mechanisms that lead to the regulation of NLRP3 inflammasome expression and activation in human dental pulp fibroblasts. Mol Immunol 2015; 66(2): 253-262.

12. Peng K, Zhang J, Meng XW, Liu HY, Ji FH. Optimization of Postoperative Intravenous Patient-Controlled Analgesia with Opioid-Dexmedetomidine Combinations: An Updated Meta-Analysis with Trial Sequential Analysis of Randomized Controlled Trials. Pain Physician 2017; 20(7): 569-596.

13. Smith TJ. Potential Roles of CD34+ Fibrocytes Masquerading as Orbital Fibroblasts in ThyroidAssociated Ophthalmopathy. J Clin Endocrinol Metab 2019; 104(2): 581-594.

14. Farcaş AD, Rusu A, Stoia MA, Vida-Simiti LA. Plasma leptin, but not resistin, TNF- $\alpha$ and adiponectin, is associated with echocardiographic parameters of cardiac remodeling in patients with coronary artery disease. Cytokine 2018; 103: 46-49.

15. Su L, Li N, Tang H, Lou ZY, Chong XD, Zhang CX, Su JC, Dong $X$. Kupffer cell-derived TNF- $\alpha$ promotes hepatocytes to produce CXCL1 and mobilize neutrophils in response to necrotic cells. Cell Death Dis 2018; 9(3): 323.

16. Itskovich SS, Gurunathan A, Clark J, Burwinkel M, Wunderlich $M$, Berger MR, Kulkarni A, Chetal K, Venkatasubramanian $M$, Salomonis $N$, et al. MBNL1 regulates essential alternative RNA splicing patterns in MLL-rearranged leukemia. Nat Commun 2020; 11(1): 2369.

17. Li Dong, Lixia Yang, Fengsui Liu, Haitao Zhan, Xinwei Chen. Farrerol ameliorates diabetic hepatopathy in rat model of type 2 diabetes mellitus via modulation of oxidative inflammatory stress. Trop J Pharm Res 2020; 19(1): 71-76. 